\title{
BOUNDEDNESS RESULTS FOR SOLUTIONS OF CERTAIN NONLINEAR DIFFERENTIAL EQUATIONS OF SECOND ORDER
}

\author{
Cemil TunÇ \\ Department of Mathematics, Faculty of Sciences, \\ Yüzüncü Yıl University, 65080, Van-Turkey \\ cemtunc@yahoo.com
}

\begin{abstract}
In this paper, we establish some new sufficient conditions which guarantee the boundedness and the uniform boundedness of solutions of certain nonlinear and nonautonomous differential equations of second order. By defining appropriate Liapunov functions, we obtain some new results on the subject, and examples are also provided to illustrate the feasibility of the proposed results. By this work, we extend and improve some boundedness results in the literature.
\end{abstract}

Key words and Phrases: Nonautonomous, differential equation, second order; boundedness, uniform boundedness.

\begin{abstract}
Abstrak. Dalam paper ini, kami membangun syarat cukup baru yang menjamin keterbatasan dan keterbatasan seragam dari solusi suatu persamaan differensial nonlinier tertentu dan nonautonomus derajat dua. Dengan mendefinisikan fungsi Liapunov, kami memperoleh suatu hasil baru dalam topik tersebut dan contoh-contoh diberikan untuk memberikan ilustrasi dari fisibilitas hasil yag diusulkan. Dengan penelitian ini, kami memperluas dan memperbaiki hasil-hasil dalam kajian keterbatasan.

Kata kunci: Nonautonomus, persamaan diferensial, derajat dua, keterbatasan, keterbatasan seragam.
\end{abstract}

\section{Introduction}

In applied science some practical problems concerning physics, mechanics and the engineering technique fields associated with nonlinear differential equations of second order can be found in Ahmad and Rama Mohana Rao [1], Burton [2], Hale [8] and Yoshizawa [23]. Hence, nonlinear differential equations of second order have

2000 Mathematics Subject Classification: 34D20

Received: 09-09-2010, accepted: 24-11-2010. 
been the object of intensive analysis by numerous authors. In particular, there have been extensive results on the boundedness of solutions of various nonlinear differential equations of second order in the literature. For example, for a comprehensive treatment of the subject on the boundedness of solutions, we refer the readers to books of Ahmad and Rama Mohana Rao [1], Krasovskii [11], Yoshizawa [22] and the papers of Graef [3,4], Graef and Spikes [5, 6, 7], Huang et al. [9], Jin [10], Murakami [12], Saker [13], Sun [14], Tunç [15,16,17], Tunç and Şevli [18], Tunç and Tunç [19], Villari [20], Ye et al. [21], Zhao [24], Waltman [25], Wong [26], Wong and Burton [27] and the references contained in these sources. Thus, it is worthwhile to continue to the investigation of the boundedness of solutions of nonlinear differential equations of second order in this case.

In 1963, Waltman [25] considered second order non-autonomous differential equation

$$
x^{\prime \prime}+a(t) f(x)=0 .
$$

The author establishes some sufficient conditions under which all solutions of Eq. (1) are bounded on a semi-infinite interval, and a condition under which the solutions are oscillatory. His theorems generalize classical results regarding linear systems.

Later on, in 1964, based on the results of Waltman [25], Wong [26] investigated second order nonlinear differential equation

$$
x^{\prime \prime}+a(t) f(x) g\left(x^{\prime}\right)=0,
$$

where $a, f$ and $g$ are continuous functions on $\Re_{+}=[0, \infty)$ and $\Re=(-\infty, \infty)$, respectively.

Wong [26] first proved the following theorem by using the integration test.

Theorem A (Wong [26, Theorem 1]). If in equation (2):

(i) $g\left(x^{\prime}\right)$ is a positive continuous function for all $x^{\prime}$,

(ii) $f(x)$ is an integrable function with $x f(x)>0$ and

$$
\lim _{x \rightarrow \pm \infty} \int_{0}^{x} f(s) d s=\infty,
$$

(iii) $a(t)$ is positive and non-decreasing, then all solutions of Eq. (2) are bounded.

Next, Wong [26] proved the following theorem.

Theorem B (Wong [26, Theorem 2]). If Eq. (2) is of the following from:

$$
x^{\prime \prime}+\left(a^{2}+b(t)\right) f(x) g\left(x^{\prime}\right)=0
$$

with $b(t) \rightarrow 0$ as $t \rightarrow \infty$, and $f(x)$ satisfies condition (ii) in Theorem A, then all solutions of Eq. (3) are bounded for all $t \geq 0$. 
By the foregoing theorems, Wong [26] generalized a theorem of Waltman [25] on the boundedness of solutions of Eq. (1).

In this paper, instead of Eqs. (2) and (3), we consider the non-linear differential equations of second order as follows

$$
x^{\prime \prime}+f\left(t, x, x^{\prime}\right) g\left(t, x, x^{\prime}\right)+b(t) h(x)=e\left(t, x, x^{\prime}\right),
$$

and

$$
x^{\prime \prime}+\left(a^{2}+b(t)\right) f\left(t, x, x^{\prime}\right) g\left(t, x, x^{\prime}\right)+c(t) h(x)=e\left(t, x, x^{\prime}\right),
$$

respectively, where $b, c, f, g, h$ and $e$ are continuous functions in their respective domains, $a^{2}$ is a constant, and it is assumed that the derivatives $b^{\prime}(t)$ and $c^{\prime}(t)$ exist and are continuous.

A primary purpose of this paper is to study the boundedness and the uniform boundedness of solutions of Eqs. (4) and (5). We will establish some new sufficient conditions for all solutions of Eqs. (4) and (5) to be bounded and uniform bounded. To the best of our knowledge, so far, the boundedness and the uniform boundedness of solutions of nonlinear differential equations of the form (1) and (2) have not been investigated in the literature. To prove our main results, we define four Liapunov functions. As seen, Eq. (4) is included by Eq. (5). However, the assumptions and the Liapunov functions established here for that equations, Eqs. (4) and (5), are different. This paper is especially motivated by the papers of Waltman [25], Wong [26] and that mentioned above. It is worth mentioning that the equations discussed by Waltman [25] and Wong [26], Eqs. (1), (2) and (3) are special cases of Eqs. (4) and (5). Next, Wong [26] discussed the boundedness of solutions of the mentioned equations without giving any example on the topic. In addition to the boundedness of solutions, we investigate also the uniform boundedness of the solutions and introduce four examples to show the effectiveness of our results. If applying our results to Eqs. (4) and (5), one will find that our results are different from those in the references of this paper and complement for them.

We write Eqs. (4) and (5) in system form as follows

$$
\begin{aligned}
& x^{\prime}=y, \\
& y^{\prime}=-f(t, x, y) g(t, x, y)-b(t) h(x)+e(t, x, y) .
\end{aligned}
$$

and

$$
\begin{aligned}
& x^{\prime}=y, \\
& y^{\prime}=-\left(a^{2}+b(t)\right) f(t, x, y) g(t, x, y)-c(t) h(x)+e(t, x, y),
\end{aligned}
$$

respectively.

Before introducing our main results, we remind a basic result on uniform boundedness of the solutions of a general non-autonomous system.

Consider a system of differential equations

$$
\frac{d x}{d t}=F(t, x)
$$

where $x$ is an $n$ - vector. Suppose that $F(t, x)$ is continuous in $(t, x)$ on $\Re_{+} \times D$, where $\Re_{+}$denotes the interval $[0, \infty)$ and $D$ is a connected open set in $\Re^{n}$. It is 
also assumed without loss of generality that $F(t, 0)=0$ and $D$ is a domain such that $\|x\|<H, H>0$.

Theorem 1. (Yoshizawa [22].) Suppose that there exists a Liapunov function $V(t, x)$ defined for $0 \leq t<\infty,\|x\| \geq R$, where $R$ may be large, which satisfies the following conditions:

(i) $a(\|x\|) \leq V(t, x) \leq b(\|x\|)$, where $a(r) \in C I, a(r) \rightarrow \infty$ as $r \rightarrow \infty$ and $b(r) \in C I$ ( $C I$ denotes the families of continuous increasing functions),

(ii) $\dot{V}(t, x) \leq 0$.

Then, the solutions of (8) are uniform-bounded.

\section{Description of Problems}

The first main problem of this paper is the following theorem.

Theorem 2. In addition to the basic assumptions imposed on the functions $b, f$, $g, h$ and $e$ that appear in Eq. (4), we assume that there exists a positive constant $\alpha$ such that the following assumptions hold:

(i) $f(t, x, y) g(t, x, y) y \geq 0$ for all $t \in \Re_{+}=[0, \infty)$ and $x, y \in \Re, b(t) \geq 1$, $b^{\prime}(t) \leq 0$ for all $t \in \Re_{+}, \frac{h(x)}{x} \geq \alpha$ for all $x \neq 0$,

(ii) $|e(t, x, y)| \leq|p(t)|, \int_{0}^{t}|p(s)| d s<\infty$.

Then all solutions of Eq. (4) are bounded.

Proof. Define the Liapunov function

$$
V(t, x, y)=b(t) \int_{0}^{x} h(s) d s+\frac{1}{2} y^{2}
$$

so that $V(t, 0,0)=0$ and

$$
\begin{aligned}
V(t, x, y) & \geq \int_{0}^{x} h(s) d s+\frac{1}{2} y^{2} \\
& \geq \frac{1}{2}\left(\alpha x^{2}+y^{2}\right)>0
\end{aligned}
$$

for all $x \neq 0$ and $y \neq 0$, by $b(t) \geq 1$ and $\frac{h(x)}{x} \geq \alpha>0$. 
Subject to the assumptions of Theorem 2, the time derivative of the Liapunov function $V(t, x, y)$ along a solution $(x(t), y(t))$ of $(6)$ yields that

$$
\begin{aligned}
\frac{d}{d t} V(t, x, y) & =b^{\prime}(t) \int_{0}^{x} h(s) d s-f(t, x, y) g(t, x, y) y+y e(t, x, y) \\
& \leq y e(t, x, y) \\
& \leq|e(t, x, y)||y| \\
& \leq|p(t)|+|p(t)| y^{2} \\
& \leq|p(t)|+2|p(t)| V(t, x, y)
\end{aligned}
$$

Integrating the last inequality from 0 to $t$, using the assumption $\int_{0}^{t}|p(s)| d s<\infty$ and Gronwall-Reid-Bellman inequality (see Ahmad and Rama Mohana Rao [1]), for a positive constant $K$, we obtain

$$
V(t, x, y) \leq K .
$$

In view of the above discussion, that is,

$$
V(t, x, y) \geq \frac{1}{2}\left(\alpha x^{2}+y^{2}\right) \text { and } V(t, x, y) \leq K
$$

one can conclude that there exists a positive constant $K_{1}$ such that

$$
|x(t)| \leq K_{1},\left|x^{\prime}(t)\right| \leq K_{1}
$$

for all $t \geq t_{0}$.

The proof of Theorem 2 is now completed.

Example 1. As a special case of Eq. (4), we consider the non-autonomous differential equation of second order

$$
\begin{aligned}
& x^{\prime \prime}+\left(4+t^{2}+x^{2}+x^{\prime 2}\right)\left(2+\frac{1}{1+t^{2}+x^{2}+x^{\prime 2}}\right) x^{\prime}+\left(1+e^{-t}\right)(2 x+\sin x) \\
& =\frac{1+\sin t+\sin x+\cos x^{\prime}}{1+t^{2}+x^{2}+x^{\prime 2}}
\end{aligned}
$$

with its associate system

$$
\begin{aligned}
x^{\prime} & =y, \\
y^{\prime} & =-\left(4+t^{2}+x^{2}+y^{2}\right)\left(2+\frac{1}{1+t^{2}+x^{2}+y^{2}}\right) y-\left(1+e^{-t}\right)(2 x+\sin x) \\
& +\frac{1+\sin t+\sin x+\cos y}{1+t^{2}+x^{2}+y^{2}} .
\end{aligned}
$$

Hence

$$
f(t, x, y) g(t, x, y) y=\left(4+t^{2}+x^{2}+y^{2}\right)\left(2+\frac{1}{1+t^{2}+x^{2}+y^{2}}\right) y^{2} \geq 0, t \geq 0,
$$




$$
\begin{gathered}
b(t)=1+e^{-t} \geq 1, \\
b^{\prime}(t)=-e^{-t} \leq 0, \\
h(x)=2 x+\sin x, \\
\frac{h(x)}{x}=2+\frac{\sin x}{x} \geq 1,(x \neq 0), \\
e(t, x, y)=\frac{1+\sin t+\sin x+\cos y}{1+t^{2}+x^{2}+y^{2}}, \\
|e(t, x, y)| \leq \frac{4}{1+t^{2}}=|p(t)|, \\
\int_{0}^{\infty}|p(s)| d s=\int_{0}^{\infty} \frac{4}{1+s^{2}} d s=2 \pi<\infty .
\end{gathered}
$$

The above discussion shows that all the assumptions of Theorem 2 hold. Then, we conclude that all solutions of the forgoing equation are bounded.

The second main problem of this paper is the following theorem.

Theorem 3. In addition to the all assumptions of Theorem 2, except $x h(x) \geq \alpha x^{2}$ and $b(t) \geq 1$, we assume that

$$
1 \leq b(t) \leq b_{0} \text {, where } b_{0} \text { is a positive constant, }
$$

$$
x h(x)>0 \text { for all } x \neq 0 \text { and } \int_{0}^{x} h(s) d s \rightarrow+\infty \text { as }|x| \rightarrow \infty .
$$

Then all solutions of Eq. (4) are uniform-bounded.

Proof. Define the Liapunov function

$$
V_{1}(t, x, y)=\exp \left(-2 \int_{0}^{t}|p(s)| d s\right)\left\{b(t) \int_{0}^{x} h(s) d s+\frac{1}{2} y^{2}+1\right\}
$$

so that

$$
\begin{aligned}
\exp \left(-2 \int_{0}^{\infty}|p(s)| d s\right)\left\{\int_{0}^{x} h(s) d s+\frac{1}{2} y^{2}+1\right\} & \leq V_{1}(t, x, y) \\
& \leq b_{0} \int_{0}^{x} h(s) d s+\frac{1}{2} y^{2}+1 .
\end{aligned}
$$

Hence, we arrive at condition (i) of Theorem 1, which holds by the assumption $\int_{0}^{x} h(s) d s \rightarrow+\infty$ as $|x| \rightarrow \infty$. 
By a direct calculation and the assumptions of Theorem 3, the time derivative of the Liapunov function $V_{1}(t, x, y)$ along the system (6) gives that

$$
\begin{aligned}
\frac{d}{d t} V_{1}(t, x, y) & =-2|p(t)| \exp \left(-2 \int_{0}^{t}|p(s)| d s\right)\left\{b(t) \int_{0}^{x} h(s) d s+\frac{1}{2} y^{2}+1\right\} \\
& +\exp \left(-2 \int_{0}^{t}|p(s)| d s\right)\left\{b^{\prime}(t) \int_{0}^{x} h(s) d s-f(t, x, y) g(t, x, y) y+y e(t, x, y)\right\} \\
& \leq-2|p(t)| \exp \left(-2 \int_{0}^{t}|p(s)| d s\right)\left(\frac{1}{2} y^{2}+1\right) \\
& +|p(t)| \exp \left(-2 \int_{0}^{t}|p(s)| d s\right)+|p(t)| \exp \left(-2 \int_{0}^{t}|p(s)| d s\right) y^{2} \\
& \leq-|p(t)| \exp \left(-2 \int_{0}^{t}|p(s)| d s\right) \leq 0 .
\end{aligned}
$$

Thus, we conclude that the solutions of Eq. (4) are uniform-bounded.

Example 2. Consider the second order non-autonomous differential equation

$$
\begin{aligned}
& x^{\prime \prime}+\left(4+t^{2}+x^{2}+x^{\prime 2}\right)\left(2+\frac{1}{1+t^{2}+x^{2}+x^{\prime 2}}\right) x^{\prime}+2\left(1+e^{-t}\right)\left(x+\frac{x}{1+x^{2}}\right) \\
& =\frac{1+\sin t+\sin x+\cos x^{\prime}}{1+t^{2}+x^{2}+x^{\prime 2}} .
\end{aligned}
$$

It is clear that

and

$$
\begin{aligned}
& 2 \geq 1+e^{-t}, b_{0}=2 \\
& h(x)=2 x+\frac{2 x}{1+x^{2}}
\end{aligned}
$$

$$
\int_{0}^{x} h(s) d s=2 \int_{0}^{x}\left(s+\frac{s}{1+s^{2}}\right) d s=x^{2}+\ln \left(1+x^{2}\right) \rightarrow \infty \text { as }|x| \rightarrow \infty .
$$

Taking into account the above discussion and that in Example 1, it follows that all the assumptions of Theorem 3 hold. Thus, we arrive at all solutions of the above equation are uniform bounded.

The third main problem of this paper is the following theorem.

Theorem 4. In addition to the basic assumptions imposed on the functions $b, c$, $f, g, h$ and $e$ that appear in Eq. (5), we assume that there exist positive constants $c_{0}$ and $\alpha$ such that the following assumptions hold:

(i)

$$
\begin{gathered}
a^{2}+b(t) \geq 0 \text { for all } t \in \Re_{+}, \\
f(t, x, y) g(t, x, y) y \geq 0 \text { for all } t \in \Re_{+} \text {and } x, y \in \Re,
\end{gathered}
$$




$$
c_{0} \geq c(t) \geq 1, c^{\prime}(t) \geq 0 \text { for all } t \in \Re_{+}, \frac{h(x)}{x} \geq \alpha \text { for all } x \neq 0,
$$

(ii)

$$
|e(t, x, y)| \leq|p(t)|, \int_{0}^{t}|p(s)| d s<\infty .
$$

Then all solutions of Eq. (5) are bounded.

Proof. Define the Liapunov function

$$
V_{2}(t, x, y)=\int_{0}^{x} h(s) d s+\frac{1}{2 c(t)} y^{2}
$$

so that $V_{2}(t, 0,0)=0$, and

$$
\begin{aligned}
V_{2}(t, x, y) & =\int_{0}^{x} h(s) d s+\frac{1}{2 c(t)} y^{2} \\
& \geq \frac{1}{2} \alpha x^{2}+\frac{1}{2 c_{0}} y^{2}>0
\end{aligned}
$$

for all $x \neq 0$ and $y \neq 0$, by $c_{0} \geq c(t) \geq 1$ and $\frac{h(x)}{x} \geq \alpha>0$.

Subject to the assumptions of Theorem 4 , the time derivative of the Liapunov function $V_{2}(t, x, y)$ along a solution $(x(t), y(t))$ of $(7)$ yields that

$$
\begin{aligned}
\frac{d}{d t} V_{2}(t, x, y) & =-\frac{c^{\prime}(t)}{2 c^{2}(t)} y^{2}-\frac{\left(a^{2}+b(t)\right)}{c(t)} f(t, x, y) g(t, x, y) y+\frac{1}{c(t)} y e(t, x, y) \\
& \leq \frac{1}{c(t)} y e(t, x, y) \\
& \leq|p(t)|+|p(t)| y^{2} .
\end{aligned}
$$

Proceeding as in Theorem 2, one can complete the rest of the proof. Therefore, we omit the details.

Example 3. Let us consider the second order non-autonomous and nonlinear differential equation

$$
\begin{aligned}
& x^{\prime \prime}+(4-3 \sin t-\cos t)\left(4+t^{2}+x^{2}+x^{\prime 2}\right)\left(2+\frac{1}{1+t^{2}+x^{2}+x^{\prime 2}}\right) x^{\prime} \\
& +\left(2-\frac{1}{1+t^{2}}\right)(2 x+\sin x)=\frac{1+\sin t+\sin x+\cos x^{\prime}}{1+t^{2}+x^{2}+x^{\prime 2}} .
\end{aligned}
$$

Hence, we have the following estimations:

$$
\begin{gathered}
a^{2}+b(t)=4-3 \sin t-\cos t \geq 0 \\
c(t)=2-\frac{1}{1+t^{2}}, \\
c_{0}=2 \geq 2-\frac{1}{1+t^{2}} \geq 1,
\end{gathered}
$$




$$
c^{\prime}(t)=\frac{2 t}{\left(1+t^{2}\right)^{2}} \geq 0, t \geq 0 \text {. }
$$

By noting the above discussion and that in Example 1, it follows that all the assumptions of Theorem 4 hold. Thus, all solutions of the above equation are bounded.

The last main problem of this paper is the following theorem.

Theorem 5. In addition to all the assumptions of Theorem 4 , except $x h(x) \geq \alpha x^{2}$, we assume that

$$
x h(x)>0 \text { for all } x \neq 0 \text { and } \int_{0}^{x} h(s) d s \rightarrow+\infty \text { as }|x| \rightarrow \infty .
$$

Then all solutions of Eq. (5) are uniform-bounded.

Proof. Define the Liapunov function

$$
V_{3}(t, x, y)=\exp \left(-2 \int_{0}^{t}|p(s)| d s\right)\left\{\int_{0}^{x} h(s) d s+\frac{1}{2 c(t)} y^{2}+1\right\}
$$

so that

$$
\begin{aligned}
\exp \left(-2 \int_{0}^{\infty}|p(s)| d s\right)\left\{\int_{0}^{x} h(s) d s+\frac{1}{2 c_{0}} y^{2}+1\right\} & \leq V_{3}(t, x, y) \\
& \leq \int_{0}^{x} h(s) d s+\frac{1}{2} y^{2}+1
\end{aligned}
$$

Hence, we arrive at condition (i) of Theorem 1, which holds by the assumption $\int_{0}^{x} h(s) d s \rightarrow+\infty$ as $|x| \rightarrow \infty$.

By a direct calculation and the assumptions of Theorem 5 , the time derivative of the Liapunov function $V_{3}(t, x, y)$ along a solution $(x(t), y(t))$ of system $(7)$ gives 
that

$$
\begin{aligned}
\frac{d}{d t} V_{3}(t, x, y) & =-2|p(t)| \exp \left(-2 \int_{0}^{t}|p(s)| d s\right)\left\{\int_{0}^{x} h(s) d s+\frac{1}{2 c(t)} y^{2}+1\right\} \\
& +\exp \left(-2 \int_{0}^{t}|p(s)| d s\right)\left\{-\frac{c^{\prime}(t)}{c^{2}(t)} y^{2}-\frac{a^{2}+b(t)}{c(t)} f(t, x, y) g(t, x, y) y\right\} \\
& +\frac{1}{c(t)} \exp \left(-2 \int_{0}^{t}|p(s)| d s\right) y e(t, x, y) \\
& \leq-2|p(t)| \exp \left(-2 \int_{0}^{t}|p(s)| d s\right)\left(\frac{1}{2} y^{2}+1\right) \\
& +|p(t)| \exp \left(-2 \int_{0}^{t}|p(s)| d s\right)+|p(t)| \exp \left(-2 \int_{0}^{t}|p(s)| d s\right) y^{2} \\
& \leq-|p(t)| \exp \left(-2 \int_{0}^{t}|p(s)| d s\right) \leq 0 .
\end{aligned}
$$

Hence, we conclude that the solutions of Eq. (5) are uniform-bounded.

Example 4. Consider the second order non-autonomous and nonlinear differential equation:

$$
\begin{aligned}
& x^{\prime \prime}+(4-3 \sin t-\cos t)\left(4+t^{2}+x^{2}+x^{\prime 2}\right)\left(2+\frac{1}{1+t^{2}+x^{2}+x^{\prime 2}}\right) x^{\prime} \\
& +2\left(2-e^{-t}\right)\left(x+\frac{x}{1+x^{2}}\right)=\frac{1}{1+t^{2}+x^{2}+x^{\prime 2}} .
\end{aligned}
$$

In view of the discussion in Example 3 and the above equation, it follows that all the assumptions of Theorem 5 holds. Hence, we conclude that all solutions of the above equation are uniform bounded.

Remark 1. In the proof of Theorem 2 and Theorem 4 we did not use Theorem 1 of Yoshizawa [22], but we used it in the proof of Theorem 3 and Theorem 5.

Remark 2. Theorems 2-5 raise some new results on the boundedness and the uniform boundedness of solutions of second order non-autonomous and nonlinear differential equations. This case is an improvement on the subject.

Remark 3. The assumptions of our main theorems are elegant and understandable, and they can also be easily applied to general second order non-autonomous and nonlinear differential equations.

That is to say the following:

Our equations, Eq. (4) and Eq. (5), include and improve that discussed by Waltman [25] and Wong [26]. Our findings can be viewed as complementary results for the boundedness results obtained by Waltman [25], Wong [26] and that in the 
references of this paper. Next, the applicability of our assumptions can be easily confirmed.

Remark 4. Theorems 3 and 5 give some additional new results to that of by Waltman [25, Theorem 1] and Wong [26]. The procedures used in proofs of our main problems are clear and comprehensible.

\section{References}

[1] Ahmad, S., Rama Mohana Rao, M., Theory of Ordinary Differential Equations with Applications in Biology and Engineering. Affiliated East-West Press Pvt. Ltd., New Delhi, 1999.

[2] Burton, T. A., Stability and Periodic Solutions of Ordinary and Functional Differential Equations, Academic Press, Orland, FL., 1985.

[3] Graef, John R., "On the Generalized Liénard Equation with Negative Damping", J. Differential Equations 12 (1972), 34-62.

[4] Graef, John R., "Some Boundedness Results for Nonautonomous Second Order Nonlinear Differential Equations", Abh. Math. Sem. Univ. Hamburg 49 (1979), 70-73.

[5] Graef, John R. and Spikes, Paul W., "'Asymptotic Behavior of Solutions of a Second Order Nonlinear Differential Equation", J. Differential Equations 17 (1975), 461-476.

[6] Graef, John R., Spikes, Paul W., "Asymptotic Properties of Solutions of a Second Order Nonlinear Differential Equation", Publ. Math. Debrecen 24:1-2 (1977), 39-51.

[7] Graef, John R., Spikes, Paul W., "Boundedness and Convergence to Zero of Solutions of a Forced Second-order Nonlinear Differential Equation", J. Math. Anal. Appl. 62:2 (1978), 295-309.

[8] Hale, J. K., Theory of Functional Differential Equations, Springer-Verlag, New York, 1977.

[9] Huang, L., Cheng, Y., Wu. J, "Boundedness of Solutions for a Class of Nonlinear Planar Systems", Tohoku Math. J. 54 (2002), 393-419.

[10] Jin, Zhou, "Boundedness and Convergence of Solutions of a Second-order Nonlinear Differential System", J. Math. Anal. Appl. 256:2 (2001), 360-374.

[11] Krasovskii, N. N., Stability of Motion, Stanford Univ. Press, Stanford, CA., 1963.

[12] Murakami, S., "Asymptotic Behavior of Solutions of Some Differential Equations", J. Math. Anal. Appl. 109 (1985), 534-545.

[13] Saker, S. H., "Boundedness of Solutions of Second-order Forced Nonlinear Dynamic Equations", Rocky Mountain J. Math. 36:6 (2006), 2027-2039.

[14] Sun, S., "Boundedness and Asymptotic Behavior of Solutions of a Second-order Nonautonomous System" ( Chinese), J. Ocean Univ. China Nat. Sci. 36:3 (2006), 397-400.

[15] Tunç, C., "Some New Stability and Boundedness Results on the Solutions of the Nonlinear Vector Differential Equations of Second Order", Iran. J. Sci. Technol. Trans. A Sci. 30:2 (2006), 213-221.

[16] Tunç, C., "A New Boundedness Theorem for a Class of Second Order Differential Equations", Arab. J. Sci. Eng. Sect. A Sci. 33:1 (2008), 83-92.

[17] Tunç, C., "A Note on Boundedness of Solutions to a Class of Non-autonomous Differential Equations of Second Order", Appl. Anal. Discrete Math. 4 (2010), 361-372.

[18] Tunç, C., Şevli, H., "Stability and Boundedness Properties of Certain Second-order Differential Equations", J. Franklin Inst. 344:5 (2007), 399-405.

[19] Tunç, C., Tunç, E., "On the Asymptotic Behavior of Solutions of Certain Second-order Differential Equations", J. Franklin Inst. 344:5 (2007), 391-398.

[20] Villari, G., "On the Qualitative Behavior of Solutions of the Li' enard Equation", J. Differential Equations 67 (1987), 267-277.

[21] Ye, Guo-Rong, Ding, Hui-Sheng, Wu, Xi-Lang, "Uniform Boundedness of Solutions for a Class of Liénard Equations", Electron. J. Differential Equations 97 (2009), 5 pp. 
[22] Yoshizawa, T., "Asymptotic Behavior of Solutions of a System of Differential Equations", Contributions to Differential Equations 1 (1963), 371-387.

[23] Yoshizawa, T., "Asymptotic Behaviors of Solutions of Differential Equations", Differential equations: qualitative theory, Vol. I, II (Szeged, 1984), 1141-1164, Colloq. Math. Soc. János Bolyai, 47, North-Holland, Amsterdam, 1987.

[24] Zhao, Liqin, "The Continuation of Solutions for Certain Nonlinear Differential Equations and Its Applications", J. Math. Anal. Appl. 329:2 (2007), 1127-1138.

[25] Waltman, P., "Some Properties of Solutions of $u^{\prime \prime}(t)+a(t) f(u) g\left(u^{\prime}\right)=0$ ", Monatsh. Math. 67 (1963), 50-54.

[26] Wong, James S. W., "A Note on Boundedness Theorems of Certain Second Order Differential Equations", SIAM Rev. 6 (1964), 175-176.

[27] Wong, J. S. W.; Burton, T. A., "Some Properties of Solutions of $u^{\prime \prime}+a(t) f(u)=0$. II", Monatsh. Math. 69 (1965), 368-374. 